\title{
Yaragraphen= Regifter.
}

\section{Strafprojep̧ordแuแ!}

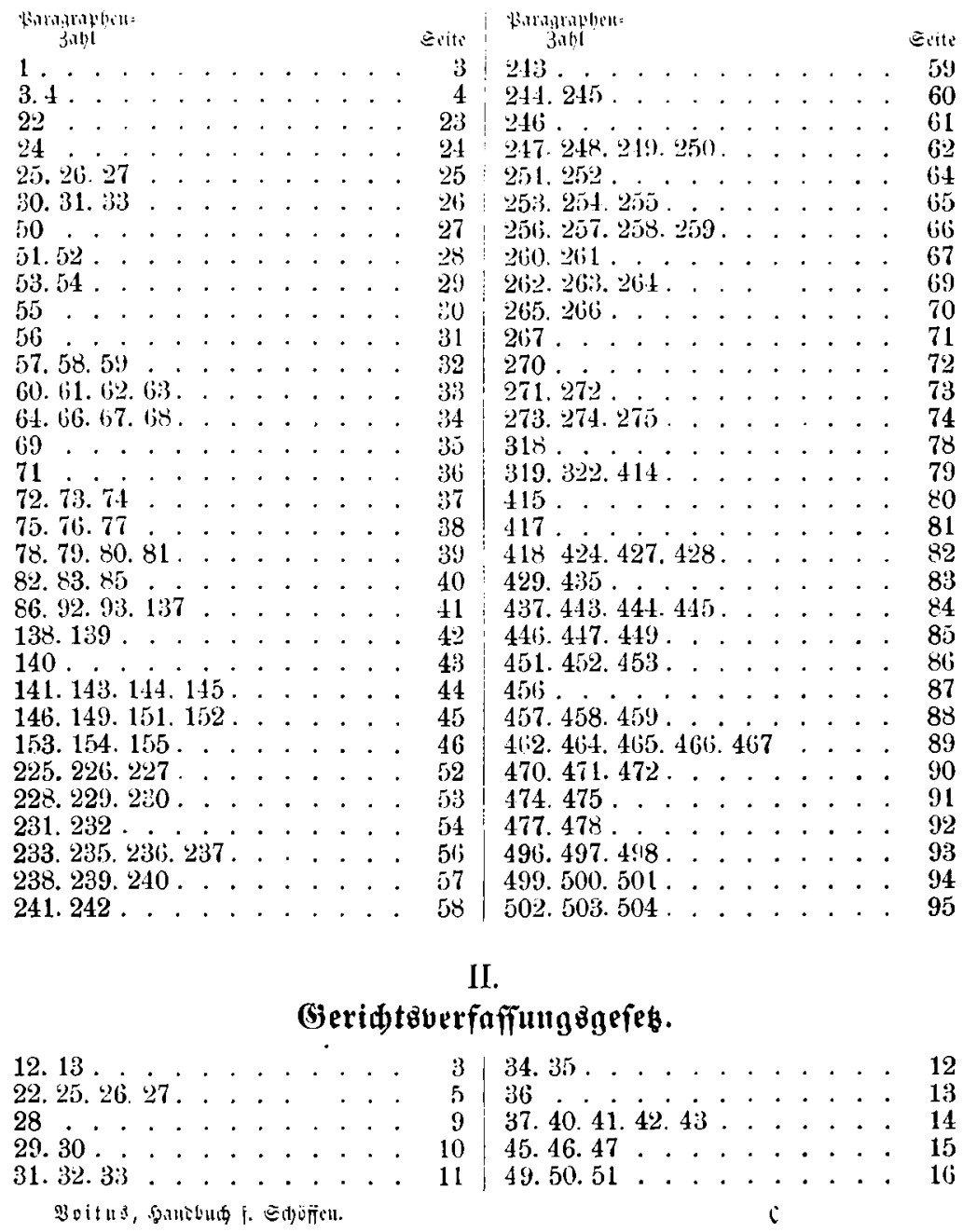


XXVI

\$aragrapben=

52.53 .

54. 55.56

59. 72.73 .74

75

170. 173. 174. 175

176. 177. 178

179. 180. 181. 184 .
Baragrałben=9iegifter.

\begin{tabular}{|c|c|c|c|c|c|}
\hline Erite & Wuriglathben= & & & & Seite \\
\hline 17 & $185.186 .187 .$. & . & & . & 50 \\
\hline 18 & 185.190 .191 .192 .193 & . & 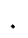 & . & 51 \\
\hline 19 & $194 . . \cdot \cdot . \cdot$. & . & . & . & 75 \\
\hline 20 & 195.196 & . & . & . & 76 \\
\hline 47 & 197.198. & . & . & . & 77 \\
\hline 48 & 199.200 & - & . & . & 78 \\
\hline 49 & & & & & \\
\hline
\end{tabular}

III.

Strafigefeb̧bud).

\begin{tabular}{|c|c|c|c|c|c|c|c|c|c|c|c|c|c|c|c|c|c|c|c|}
\hline 1. 2 & & & - & & & & & & & & & & & & & & & & \\
\hline 3. 10.11 . & & - & - & $\cdot$ & • & . & & & 108 & 191. 192. 193 & & & & & & & & & \\
\hline 2. 14.16 & & & - & & . & - & & & 109 & 194.195 .196$. & & 197 & & 198 & & & & & \\
\hline 18.19 & 20 . & . & . & - & . & & • & & 110 & 199 . . . & - & . & & & & & & & \\
\hline 7. 28 & & • & - & . & - & . & . & & 11 & 200.223 . & & & & & & & & & \\
\hline 1. 32 & & . & . & . & . & . & . & & 11 & $223 a .624 .226$ & & & & & & & & & \\
\hline 4. 35 & & • & 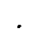 & . & & 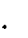 & . & & & 230.231 .232 & & & & & & & & & \\
\hline 41 & & . & & . & & & & & & 233.241 .242 & & & & & & & & & \\
\hline & & • & • & . & • & . & & & 11 & $243 . .$. & & . & & & & & & & \\
\hline 46 & & . & . & - & & & & & 117 & $246 . .$. & & . & & & & & & & \\
\hline . & & • & • & - & & & & & 11 & 247 . . . & & . & . & & & & & & \\
\hline & & . & . & . & & & . & & 11 & 3. 257. & • & . & . & . & & & & & \\
\hline 50 . & & • & . & . & & . & . & & 120 & 258.259 & & . & . & & & & & & \\
\hline & . & • & . & - & & • & • & & 121 & 261.262 & & . & . & . & & & & & \\
\hline 53. & - & • & . & - & . & • & & . & 122 & . $\cdot$ & & . & . & . & & & & & \\
\hline & & . & . & . & & & & & 12 & 264.273 . & & . & . & . & & & & & \\
\hline 66 . & & & . & & & & & & 16 & 5. 276 . & & . & . & & & & & & \\
\hline & & . & • & . & & & & & 12 & . & • & . & & & & & & & \\
\hline 9.60 & & . & . & . & & & • & & 120 & 292 . & & . & . & . & & & & & \\
\hline & & . & . & . & & - & . & & 12 & 294.295 & & . & . & . & & & & & \\
\hline 78 & & . & . & . & - & $\cdot$ & & & 12 & 298.299 & & . & . & . & & & & & \\
\hline & & • & . & & & . & . & & 13 & 300.303 . . & & . & . & . & & & & & \\
\hline & & - & & & & & • & & 13 & 304 . . . & & . & ${ }^{\circ}$ & & & & & & \\
\hline 117. & & . & & & & & & & 132 & 320 . & & & & & & & & & \\
\hline 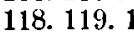 & 120. & . & . & . & & & • & & 133 & 327. & & & & & & & & & \\
\hline & . . & . & . & . & & & - & & 134 & 328. 359 . & & - & & & & & & & \\
\hline & & • & . & . & & & & & 136 & 360 . . & & . & . & & & & & & \\
\hline 137. & & & & & & & & & 13 & 361 . . & & & & & & & & & \\
\hline 45 . & & & & & & & & & & 362.363. & & & & & & & & & \\
\hline ). 1 & 152. & $\cdot$ & & & & & • & & 13 & 364.365 . & & & & & & & & & \\
\hline & 183. & . & & & & & . & & & & & & & & & & & & \\
\hline & & & & & & & & & & 366 a. 367 & & & & & & & & & \\
\hline & & & & & & & & & 14 & 368 . . & & & & & & & & & \\
\hline 188 & & & & & & & & & 144 & 369 & & & & & & & & & \\
\hline & & & & & & & & & 145 & $370 .$. & & & & & & & & & \\
\hline
\end{tabular}

